\title{
NUEVA HIPÓTESIS SOBRE LA PERSONALIDAD DE BARAY DE REMINŶOO
}

\author{
Luis F. Bernabé Pons*
}

Desde que en 1958 Leonard P. Harvey diese noticia del manuscrito aljamiado Dd. 9.49 de la Biblioteca Universitaria de Cambridge ${ }^{1}$, un nuevo y elusivo personaje venía a añadirse como inesperada pareja a la figura del más famoso de los autores de la literatura aljamiada, el Mancebo de Arévalo. En este manuscrito estaba contenido un Breve Compendio de nuestra Santa Ley y Çunna que en su comienzo se anunciaba como colaboración entre el autor castellano y un alfaquí, Baray de Reminŷo:

"El b(e)reve compendi(y)o de nuest(a)ra santa ley y sunna que acopiló el onrrado sabidor, alfaqi del alyamaca de los muslimes de Cad(e)rete, que se llamaba B(a)ray de Reminyo, con acuerdo y ayuda de otros muchos alimes, muy doctos y fasalados de la nobleza deste reyno de Aragón, y en espesi(y)al con ayuda de un mansebo escolano, castellano, natural de Arévalo, muy esperto y doct(i)rinado en la lectura carabiga, ebraica, g(i)ri(y)ega y latina, y-en la alŷemicada muy ladino..." ${ }^{2}$.

Todas las investigaciones, del propio Harvey o de otros autores, que posteriormente se han acercado a la figura del Mancebo, se han detenido también en la figura de este alfaquí, trayendo a colación éste y otros textos contenidos en el manuscrito y llegando a una serie de conclusiones que resumimos brevemente: se trataría de la figura de un alfaquí aragonés de la villa de Cadrete (cerca de Zaragoza), que escribe unos pocos años después de la conversión forzada de los mudéjares aragoneses un compendio islámico en colaboración o co-redacción (pues no están bien delimitados los límites de

\footnotetext{
* Universidad de Alicante.

1. «Un manuscrito aljamiado en la Biblioteca de la Universidad de Cambridge», Al-Andalus, Madrid, XXIII, 1, 1958, pp. 49-74.

2. Breve Compendio, ms. de la Universidad de Cambridge Dd. 9. 49, página de título apud L.P. HARVEY, op. cit., p. 65. Modernizo en las citas la transcripción del sistema aljamiado, así como la acentuación del texto, aunque conservo en esta cita concreta, por única vez, las vocales anaptíticas y las semiconsonantes epentéticas entre paréntesis.
} 
autoría en el texto) con el Mancebo de Arévalo y que narra una serie de acontecimientos de interés que han servido, principalmente, para ayudar a la fechación del texto y dar un dibujo aproximado de su ambiente.

El propio profesor Harvey, en ese mismo artículo de Al-Andalus y en trabajos posteriores, había confesado su perplejidad ante el nombre del alfaquí, perplejidad que también comparten otros autores, que llegan a concluir que no se trata de un nombre islámico ${ }^{3}$. Harvey ofrece la posibilidad de un derivado de Petrus ${ }^{4}$, a partir de una sugerencia de Lévi-Provençal, de una deformación del nombre catalán Pere ${ }^{5}$.

Sin embargo, es a partir de una interpretación de este nombre cuando los datos ofrecidos por el Breve Compendio pueden ser interpretados de otra forma, pensamos que coherente, que ofrece una nueva luz sobre la figura de este alfaquí escritor.

\section{EL NOMBRE: "BARAY DE REMINŶO"}

Como hemos señalado, con ser pocos los datos que la obra del alfaquí nos suministra en su obra, ni siquiera su nombre parecía dar más pistas en torno a su persona. Sin embargo, teniendo en cuenta las características lingüísticas y ortográficas del aljamiado en el que está escrito el manuscrito de Cambridge, el nombre puede ser contemplado de otra manera, y ésta es, indudablemente, islámica.

Como es conocido, entre las, digamos "normas" del aljamiado, se encuentra el desarrollo en la grafía de una vocal anaptíctica en el interior de un grupo consonántico ${ }^{6}$. Si tenemos presente esta norma, bastante generalizada en las obras aljamiadas, de la misma forma que existe en el texto un $f(a)$ ray Esteban Martel que es evidentemente un fray Esteban Martel, tendríamos entonces un nombre $B(a)$ ray o Bray, que, desde el punto de vista de la onomástica mudéjar y morisca ya nos resulta algo más familiar.

En efecto, el nombre árabe Ibrāhīm, común entre la comunidad hispanomusulmana, se halla registrado en la documentación con variantes diversas según sea la zona que en cada caso tratemos: Ibraem, Brahin, Brafim... Como los frecuentísimos fenómenos atestiguados que afectan a

3. Vid. Gerard WIEGERS, Yça Gidelli (fl. 1450), his antecedents and successors. A historical study of Islamic Literature in Spanish and Aljamiado, Leiden, 1991, p. 155.

4. L.P. HARVEY, The Literary Culture of the Moriscos (1492-1609). A study based on the extant mss. in Arabic and Aljamia, Oxford, 1958 (Tesis doctoral inédita), p. 371.

5. L.P. HARVEY, «El alfaquí de Cadrete, Baray de Reminjo y El Breve Compendio de Nuestra Santo Ley y Sunna», II Jornadas Internacionales de Cultura Islámica "Aragón vive su historia", Madrid, 1990 , p. 216.

6. Vid. Ramón Menéndez Pidal, Poema de Yúçuf. Materiales para su estudio, Granada, 1952, pp. 39-40. 
este nombre pueden ser tanto la pérdida de la I- inicial pretónica, como la evolución variada del grupo interior o bien la pérdida de la $-\mathrm{m}$ final, en este sentido, no resulta particularmente extraño, hablando desde el punto de vista de la Historia de la Onomástica, encontrar otra forma que haya perdido esta vocal inicial.

Tendríamos entonces un Bray como resultado final de un Ibrāhïm con el paso intermedio de un Ibray. Pero lo dicho hasta ahora no deja de ser una especulación teórica: habría que sustentarlo con testimonios de la existencia de esta forma particular. $Y$ estos testimonios existen, y en una zona que les resultará familiar a todos aquéllos que se han interesado alguna vez por Baray: Navarra.

En el libro de Mercedes García Arenal y Béatrice Leroy, Moros y judios en Navarra en la baja Edad Media, en la parte que la primera autora dedica a los mudéjares navarros durante los siglos XII al XVI encontramos atestiguados unos cuantos Ybray alternando con Ybraym como la forma característicamente navarra del Ibrāhīm árabe: Ybray de Goadalajara, Ybray de Roxores, Ybray el Royo o Ybray de Taraçona están recogidos en unas cuentas de las rentas del rey de lo recogido en Valtierra en 1424, mientras que la mujer de un Ybray de Vatal es mencionada en las testificaciones sobre un hurto que tuvo lugar en la morería de Tudela el 15 de enero de $1513^{7}$.

Pensamos entonces que es esta forma onomástica la que aparece recogida en el Breve Compendio bajo la forma de su transcripción aljamiada, un $B($ a)ray que correspondería a un antiguo Ibrāhim evolucionado por el habla de los habitantes del reino de Navarra y que sería una de las formas utilizadas por éstos en pleno siglo XVI.

Esta presencia de Navarra relacionada con el Breve Compendio no es, al menos como sospecha, nueva. Ya Julián Ribera y Miguel Asín -y así lo recoge también Harvey en 1958- en su Catálogo de los manuscritos árabes y aljamiados se habían hecho eco de lo escrito por un morisco en el manuscrito número LXII de la Junta, quien señalaba: "Y anxí mexmo lo hallamox en otro libro en la Ribera que xe llama el brebe compeño, que fue xacado de un mançebo muy xabio y de un alfaquí con él, y fue corregido de los xabios de

7. Mercedes García Arenal y Béatrice Leroy, Moros y judios en Navarra en la baja Edad Media, Madrid, 1984, docs. XXXV (pp. 116-117), XLVII (p. 130), también pp. 21, 24 (n. 6), 29; a título de ejemplo, p. 44n., venta de bienes en mayo de 1516 en Tudela: "Primeramente vna casa mia que yo he y tengo situada en la dicha moreria en el barrio llamado de Vililla en la caleja de mastre Ybray, que afruentan de la vna parte con casas de Mahoma Atorrelli et de la otra parte con casas del dicto mastre Ybray (...) et de la otra parte con casas de Jayel Cortobi, alfaqui de la dicta moreria (...). Item vn guerto mio ... que afruenta de la vna parte ... et de la otra parte con guerto de Ybray Vatal, moro vezino de la dicta moreria...". También en Ikio OZAKI ( El régimen tributario y la vida económica de los mudéjares de Navarra», Anuario de Estudios Medievales, Barcelona, 16, 1986, pp. 319-368) se halla recogido un "Ybray el Bayo" (p. 365, n. 221) en un documento de 1516 acerca del derecho de agua en Cortes. 
Aragón y de los alfaquíex..." 8 , lo que había llevado a pensar a Harvey como posibilidad, rechazada finalmente por él, que la aljama de la que Reminŷo era alfaquí no era Cadrete, cerca de Zaragoza, sino Cadreita, en la Ribera del Ebro en Navarra ${ }^{9}$.

Sería entonces un Ibrāhim de Reminŷo navarro, posiblemente antiguo alfaquí de la aljama de Cadreita, que escribe indudablemente en Aragón su tratado. Por supuesto, esta misma explicación es válida para el otro Baray que aparece en el Breve Compendio, Baray de Balera o Ibrāhim de Valera, el muftí y sedichén (quizás un raro participio en el sentido de "sedente", "tener la sede" $\mathrm{e}^{10}$ de Almagro, a quien es solicitada una fatwà sobre una cuestión económica. Pero, claro, también es aplicable al Baray que aparece en la Tafçira del Mancebo de Arévalo, Baray González de Ávila. Sería la forma navarra del nombre (consagrada ahora casi como "forma aljamiada") la que el autor utiliza continuamente en todas las ocasiones en las que en el texto aparece un Ibrāhīm contemporáneo a él ${ }^{11}$, por más que los otros dos personajes probablemente no se autodenominarían asi ${ }^{12}$.

Otro punto oscuro del texto de Cambridge puede venir en apoyo de esta hipótesis: en el conocido pasaje del manuscrito en el que Reminyo habla con Fray Esteban Martel (pasaje que más adelante comentaremos completo), el fraile carmelita, ante la queja hacia el Papa que efectúa el alfaquí navarro respecto a la situación de los musulmanes, hace referencia a un decreto:

"Yo [i.e. Reminŷo] le respondí que me espantaba de su santidad aber consedido y decretado tal cosa, y respondióme que el Papa no abía consentido en ello, sino que por el decreto Mantuano nos abian sentensiado y que firmó su santedad la sentensia por engaño de siertos cardenales franseses que conspiraron contra nosotros".

8. J. Ribera y M. Asín, Manuscritos árabes y aljamiados de la Biblioteca de la Junta, Madrid, 1912, p. 71. Vid. L.P. HARVEY, «Un manuscrito...», p. 51, n. 1.

9. Aunque piensa que la mención de la Ribera [del Ebrol se adecuaría mucho mejor a la población navarra que a la aragonesa, dada la total semejanza nominal de la población del manuscrito con el Cadrete zaragozano, Harvey se inclina finalmente por una patria aragonesa para Reminŷ: The Literary Culture..., p. 372. Pascual MAdoz (Diccionario GeográficoEstadístico-Histórico de España y sus posesiones de ultramar, Madrid, 1846, tomo V, p. 232) ofrece como nombres antiguos de la población navarra Quadreyta y Cadereyta.

10. Vid. J. Corominas, Diccionario Crítico-Etimológico Castellano e Hispánico, Madrid, 1974, vol. IV, s.v. "Sentar", s.v. "Ser", donde Corominas habla de la confusión en la evolución del castellano entre las formas verbales de ESSE y de SEDERE y que ha dado formas como sedié o sedién, atestiguada ésta última en Berceo.

11. Sólo entre sus contemporáneos, puesto que también aparecen en el Breve Compendio referencias al Ibrāhim por antonomasia, el Abraham coránico, citado por su nombre árabe correcto (Breve Compendio, fol. 6v, apud G. WIEGERS, $Y_{c ̧ a}$ Gidelli.., p. 161; fol. 246r. apud Jacqueline KaRP, El manuscrito aljamiado de la Biblioteca de la Universidad de Cambridge (folios 237v-249r). Introducción, texto y glosario, Toulouse, 1978, mémoire de maîtrise inédita, p. 76).

12. Vid. María Teresa NARVÁEZ, "Nozaita Kalderán: partera y experta en el Corán», La Torre, n.e., $3-4,1987$, p. 507. 
Sin embargo, tal referencia concreta a ese "decreto Mantuano" no parece servir de ayuda toda vez que no es conocido, 0 , al menos, no ha sido hallado por los investigadores, un decreto con ese nombre en asunto alguno referido a España o a los moriscos; no parece existir ningún decreto firmado en Mantua, o por algún Papa de Mantua, o algo parecido castigando a los mudéjares. Pienso que, en esta ocasión, Reminŷo no está utilizando ningún patronímico, sino, igual que antes, un navarrismo algo adaptado. En la Enciclopedia del Idioma de Martín Alonso ${ }^{13}$ se registra la voz "Mantuana" como un navarrismo por "Paliza, tunda", esto es, la forma característicamente navarra para la misma acepción de la voz castellana "Manta"14. De esta manera, Ibrāhīm de Reminŷo está haciendo referencia no al origen geográfico de tal decreto, sino a su consecuencia: está hablando, con este navarrismo, de un decreto punitivo o castigador que obliga a los mudéjares navarros a salir de su suelo de origen.

Quedaría pendiente la difícil cuestión del apellido del mudéjar navarro, aunque, una vez establecida su identidad navarra, no parece el problema más importante. Harvey señaló que en la obra de Pascual Boronat había encontrado el apellido Remincha ${ }^{15}$, lo que indicaba que no era un apellido desconocido entre moriscos. En efecto, en la obra de Ana Labarta sobre la onomástica de los moriscos valencianos se encuentran anotados los apellidos Remincha y Reminga como pertenecientes a dos moriscos procedentes de Aragón, esto es, un morisco y una morisca tagarinos ${ }^{16}$.

¿De dónde podría proceder el apellido? Éste es un aspecto de la investigación que todavía no ha dado sus frutos; la ŷjm que acompaña a la $n$ en el apellido daría $j$ en castellano (con pronunciación, probablemente, fricativa prepalatal) ${ }^{17}$, Ibrāhỉm de Reminjo, pues, y ch o $x$ en catalán o valenciano (Ibrahim de Remincho), aunque pensamos que no habría que descartar un posible reflejo de $\tilde{n}^{18}$. En documentos árabes de la zona de Tudela Mercedes García Arenal ha certificado que las palabras aljamiadas que allí se encuentran no transcriben la $\tilde{n}$ como es usual en aljamiado, es decir con $n \bar{u} n$ con

13. Martín Alonso, Enciclopedia del Idioma. Diccionario Histórico y Moderno de la Lengua Española (siglos XII al XX), Etimológico, Tecnológico, Regional e Hispanoamericano, tomo II, Madrid, 1958 , p. 2704.

14. Vid. María Moliner, Diccionario de Uso del Español, Madrid, 1989, tomo II, p. 340.

15. L.P. HARveY, The Literary..., p. 371. Vid. Pascual Boronat, Los moriscos españoles y su expulsión, Valencia, 1901, vol. I, p. 586: Francisco Remincha, Valencia, 1577.

16. Ana LABARTA, La onomástica de los moriscos valencianos, Madrid, 1987, p. 225: Remincha, un morisco tagarino vecino de Paterna en 1578, y procedente de "Fuentes de hebro"; Reminga, morisca tagarina avecindada en Bechí o Vall d'Uxó.

17. Vid. Álvaro GALMÉs de FuENTES, El libro de las batallas. Narraciones épico-caballerescas, Madrid, 1975, tomo II, p. 23

18. Vid., por ejemplo, María Teresa NARVÁEZ, «Preceptos para la vida cotidiana: Ética, moral y buenas costumbres en un capítulo de la Tafçira del Mancebo de Arévalo», Homenaje a Álvaro Galmés de Fuentes, Madrid-Oviedo, 1985, vol. II, pp. 621-630. 
tašdi $d\left({ }^{\omega} \dot{u}\right)$, sino con $>$ ny $<{ }^{19}$. Ya que el Compendio fue posteriormente copiado por un copista aragonés, podría quizá pensarse, de la misma forma que con Baray, en un resto dialectal de la zona navarra en el nombre del autor, puesto que en el resto de la obra el uso de $\tilde{n}$ parece responder a lo que es norma en la literatura aljamiada. En este sentido, aunque por ahora a mero título de inventario, hay que señalar que en el siglo XV está atestiguado en Navarra el apellido "de Minha"20.

\section{LA COMUNIDAD MUDÉJAR NAVARRA}

La comunidad mudéjar y morisca navarra, un poco en consonancia con la propia historia general de la región, no ha sido, ni mucho menos, objeto de la misma atención crítica que han merecido las mismas comunidades de Castilla y Aragón. Sólo recientemente una serie de trabajos monográficos inició esta línea de investigación acerca de unos grupos sociales todavía mal conocidos ${ }^{21}$.

La zona de la Ribera del Ebro, la merindad de Tudela, fue la única donde permaneció población musulmana tras la conquista cristiana de Tudela en 1119 por Alfonso el Batallador ${ }^{22}$. Región extraordinariamente rica desde el punto de vista agrícola, un importante número de musulmanes prefirió seguir allí establecido amparado por una serie de ventajosos fueros otorgados por el monarca, que buscaba evitar el éxodo masivo de un notable contingente de población y de una mano de obra experta.

La aljama de la capital, Tudela, junto con otras aljamas menores como las de Cortes, Fontellas, Ablitas, Monteagudo, Valtierra, Cascante o Cadreita albergaban una considerable comunidad de mudéjares que, bastante cohesionados y con una presencia de cierta fuerza en la sociedad navarra, tuvo un discurrir secular, bajo la autoridad cristiana, bastante estable y uniforme comparado con el de sus correligionarios castellanos o aragoneses. Este tranquilo discurrir hace que los reyes navarros concedan como contrapartida a los mudéjares unos privilegios que colocan su estatuto por encima del de sus vecinos.

19. Mercedes García Arenal, «Documentos árabes de Tarazona y Tudela», Al-Qantara, III, 1982, pp. 27-72.

20. Vid. Ricardo Cierbide Martinena, Censos de población de la Baja Navarra (1350-1353 y 1412), Tübingen, 1993, p. 137.

21. Vid., aparte de los citados de García Arenal y Ozaki, Mercedes GARCía ARENAL, "Los mudéjares en el Reino de Navarra y en la Corona de Aragón. Estado actual de su estudio», Actas del III Simposio Internacional de Mudejarismo, Teruel, 1986, pp. 175-186.

22. Vid. José María LACARra, «La fecha de la conquista de Tudela», Príncipe de Viana, VII, 1946, pp. $45-54$. 
El funcionamiento interno de las aljamas navarras dentro de estos siglos ha sido también parcialmente dibujado en estos estudios y, teniendo en cuenta las peculiaridades aludidas de unas ventajas más frecuentes generalmente de carácter fiscal y laboral otorgadas por los reyes de Navarra, su funcionamiento no parece diferir mucho del resto de las aljamas peninsulares. Importa, sin embargo, remarcar un fenómeno: en las aljamas navarras el guía espiritual de la comunidad, el alfaquí, suele asumir también las tareas de escribano. A su función de maestro y mentor de asuntos religiosos añade su función de escribano, por ser, posiblemente, una de las escasas personas que todavía conserva conocimientos (en qué cantidad no lo podemos precisar) de la lengua árabe, que, por los documentos existentes, parece no haberse perdido completamente en Navarra, incluso entrado el siglo XVI ${ }^{23}$.

Ésta es la situación que se va a mantener hasta 1516, año en que los mudéjares desaparecen como tal comunidad en Navarra. Dentro de la política exterior diseñada por Fernando el Católico a comienzos del siglo XVI Navarra quedó contemplada como un objetivo fundamental de sus aspiraciones, por formar el reino norteño una importante pieza territorial que oponer en su litigio con Luis XII de Francia, a la sazón declarado cismático por el Papa Julio II a causa de la convocatoria del llamado "conciliábulo de Pisa" en septiembre de 1511. Este concilio, reunido por el rey francés para derrocar al pontífice, provocó la reacción papal y la formación en su contra de la Liga Santa, formada por el propio Papa, Venecia, Suiza y Fernando el Católico.

Cuando el rey de Navarra Juan III Albret firmó en Blois una alianza secreta en junio de 1512 con el monarca francés, Fernando hizo circular públicamente los términos de tal tratado y decide la marcha contra Pamplona. Pero, para conceptuar y asegurar su marcha contra Navarra como la liberación de un pueblo del yugo de un príncipe cismático, solicita del Papa una bula que excomulgase a los aliados navarros del rey francés y santificase su acción contra ellos ${ }^{24}$. Aunque Fernando la dé desde un principio por otorgada $-\mathrm{y}$, de hecho, conquiste bajo esa bandera Navarra ese mismo verano-, la bula papal se hará esperar, para desespero suyo ${ }^{25}$, hasta el 18 de febrero de 1513 , en que verá la luz la bula Exigit contumacium obstinata protervitas.

23. "A pesar de la temprana fecha de la conquista cristiana y del aislamiento de los mudéjares navarros respecto a tierras islámicas, este conocimiento [del árabe] parece haberse mantenido más vivo que en otras regiones mudéjares. Aunque el hecho de que escribano, alcadí o alfaquí, o alfaquí y escribano sean generalmente una misma persona demuestra que tales conocimientos no abundaban, el hecho de que existieran, y de que los mudéjares se aferraran a ellos, dan prueba de la relativa importancia y de la cohesión interna de esta minoría y de que su estatus era comparativamente superior al de los mudéjares de otras regiones, puesto que les permitía mantener rasgos culturales en otros erosionados hasta la desaparición", M. García ARenal, Moros..., p. 38.

24. Vid. Luis Suárez Fernández y Manuel Fernández Álvarez, La España de los Reyes Católicos, tomo XVII de Historia de España de Ramón Menéndez Pidal, Madrid, 1969 (r.), pp. 721-725.

25. Vid. la correspondencia de Fernando mostrando su impaciencia sobre este asunto con su embajador en Roma Jerónimo de Vich publicada por el barón de Terrateig, Política en Italia del Rey Católico, Madrid, 1963, vol. II, pp. 214-215. 
Ya en esa fecha, Navarra era castellana de facto tras su conquista en 1512 por las tropas del Duque de Alba. La capital de la Ribera del Ebro, Tudela, recibió la visita del rey Fernando el mes de octubre, y juró en ella los fueros y privilegios de la ciudad y la morería. Sin embargo, en las Cortes de Castilla reunidas en Burgos en 1515, en las que Fernando en su discurso hará referencia solemne a la bula papal de dos años antes, queda sancionada la anexión de Navarra a Castilla y las leyes del reino castellano pasan a regir completamente al nuevo territorio ${ }^{26}$.

Entre estas leyes que pasan a aplicarse ahora ya a Navarra está, por supuesto, la célebre pragmática de 1502, que obligaba a los mudéjares a la dura opción de convertirse al cristianismo o salir desterrados de las tierras ahora castellanas. Los mudéjares navarros, enfrentados a la fuerza a esta decisión, optan en su mayoría por vender sus bienes en la primavera de 1516 y marcharse apenas unos kilómetros al sur, al reino de Aragón, donde todavía perduraría el estatuto mudéjar hasta 1525. Apenas se tienen escasas noticias acerca de si quedaron moriscos en las tierras de Navarra; Henry Lapeyre no tiene en cuenta a Navarra en su clásica obra, mientras que otros estudiosos apenas dedican algún espacio a los mudéjares navarros y absolutamente nada a los moriscos, como si su existencia acabase en 1516, cuando parece ser que, si bien escasos en número, sí quedó población musulmana, ahora morisca y criptomusulmana, en la merindad de Tudela ${ }^{27}$.

\section{El BREVE COMPENDIO. UN MUdÉJAR NAVARRo EN ARAGÓN}

Ya algunos de los pasajes de la obra publicados por Harvey llamaban un tanto la atención por lo que suponían de remitir a una autoridad superior que revisara y consultara la obra que Reminŷo y el Mancebo tenían entre manos: se hace continua mención (ver textos anteriores) a los alimes y alfaquíes del reino de Aragón que, presuntamente, ayudan, acuerdan y corrigen este texto del tratado religioso. $Y$ señalo que presuntamente porque cabe interrogarse sobre qué tipo de sabios islámicos son estos alimes y alfaquíes aragoneses que realizan encargos de tratados religiosos para después corregirlos y consensuarlos ellos mismos. Podría tratarse quizá de un grupo de mudéjares aragoneses de buena posición económica que encargan esta obra como una acción piadosa en beneficio de toda la comunidad ${ }^{28}$.

26. Vid. Manuel Colmeiro, Cortes de los Antiguos Reinos de León y Castilla, Madrid, 1884, Parte Segunda, pp. 85-91.

27. Vid. Mercedes GarCía ARenal, «Los moros de Tudela (Navarra) en torno a los años de la Conversión (1515)», Les Morisques et leur Temps, Paris, 1983, pp. 73-102.

28. Como lo hará en el exilio tunecino en la primera mitad del siglo XVII el mercader morisco aragonés Muhammad Rubio, de Villafeliche, quien paga de su bolsillo las traducciones castellanas del árabe que conforman el manuscrito D. 565 de la Biblioteca Universitaria de 
Con todo, y aceptando las palabras del manuscrito, el que la intervención del Mancebo sea acordada y corregida por esta "comunidad de alfaquíes" nos puede parecer, hasta cierto punto, lógico dado su origen castellano, y así lo reconoce el morisco autor del manuscrito LXII de la Junta ("...por cuanto el autor del libro era castellano..."), pero lo que ya no resultaría tan claro es por qué, si Ibrāhỉm mismo es un alfaquí aragonés, la necesidad de corrección por parte de sus compañeros y coterráneos aparece tan evidente.

Creo que la explicación más plausible iría en el sentido indicado: B(a)ray, o lbrāhìm, es también una persona foránea, un extranjero en Aragón, a donde ha ido desde Navarra a buscar refugio tras la conversión forzosa y donde se ha establecido para poder seguir, suponemos, con su labor de alfaquí.

Pero es que él mismo nos deja constancia en el manuscrito de Cambridge de que Aragón ha sido para él tierra nueva de llegada. En el párrafo que incluyo a continuación, que no había sido editado por Harvey en su trabajo de $1958^{29}$, nuestro alfaquí comenta una jutba que ha oído en Aragón de boca de un sabio:

"Dixo un 'âlim deste rreyno, hablando de nuestro enserramiento, 'Yo bien conosco que somos en una temporada de grande espanto, mas no por esto dexara Allāh de darnos cawtorizada si dexamos el poroo de nuestro poderío en lo que toca al presebtario mandamiento. $Y$ a cuanto la monestansa, todos la podemos usar por la bía previleyada, y con los cantares aŷenos por donde los cristianos hazen salba, pues todo cabe debaxo de buena disimulansa, porque la buena doctrina no la puede bedar ninguna ley por umana que sea, y no dexarán los nuestros dichos, si son buenos, y cuando uno da su voluntad de la mano, no está muy aparte su buena feoza. Esto dixo en su aljuba un día de alŷumu'a con otros dichos de gran documensia para nuestras almas, y de grande consuelo para nuestras aflisiones, plege a su bondad oyga nuestro duelo, y dé lugar a la buena retornada nuestra".

Y concluye Reminŷ:

"El ber unos calimes tan onrrados me daba mucho contento el hazer asiento y reposo en Aragón, sino que me destrosía ver la tierra tan infisionada por todas partes, y ver el addìn tan sin podosia que no abía ningun onor enta los presebtos; los más pasaban abadadamente con una creyensia y fe simple, pensando aquello les bastaba para su salvasión" ${ }^{\prime 30}$.

Bolonia; vid. Juan PENELLA, «Introduction au manuscrit D. 565 de la Bibliothèque Universitaire de Bologne», en M. de EPALZA y R. PETrT, Études sur les moriscos andalous en Tunisie, Madrid-Tunis, 1973, pp. 258-263. De cualquier forma, la investigación sobre la pervivencia de autoridades islámicas en Aragón no está cerrada: todavía en 1447 persistía una madrasa en la ciudad de Zaragoza desde la que escribe el alumno Muhammad ibn Ibrăhim ibn cAbd Allāh Šabatūn de Teruel; ver D. GASCÓN y GuIMBAO, Miscelánéa Turolense, Madrid, 1901; ed. facsímil, Teruel, 1993, p. 392. J. RiberA, Disertaciones y opúsculos, Madrid, 1928, tomo I, pp. 361-352.

29. Sí lo señalaba sin embargo en su tesis doctoral, op. cit., p. 370, dentro de la aclaración de autoría de diversos párrafos del Breve Compendio.

30. Breve Compendio, f. 126v. Vid. L.P. HARVEY, «El alfaquí...», p. 219. 
Ya Harvey había hecho notar su extrañeza ante el tono de este último párrafo, que no parece hecho por un natural de esas tierras, sino por alguien "que se interesa por los cambios producidos en una sociedad que no es la suya"31. Pienso que el texto es claro: Ibrāhim ha hecho asiento y reposo en Aragón, se ha establecido allí después de un viaje y desde esta nueva tierra, como forastero, comenta qué es lo que dicen las autoridades religiosas aragonesas sobre la situación de la religión en su tiempo.

Y creo, además, que el propio Ibrāhīm desliza, más o menos disimuladamente, en un momento de su discurso su verdadero lugar de proveniencia. Ya se ha visto cómo el morisco del ms. LXII de la Junta habla de la Ribera relacionándola con el Breve Compendio. Posiblemente el propio alfaquí también: en un momento del pasaje anteriormente citado en que Ibrāhim ha hablado con fray Esteban Martel, el autor incide en su método de trabajo para la obra y desarrolla toda una captatio benevolentiae para resguardarse de las críticas acerca de la oscuridad de los vocablos empleados, del mal uso de la morfología árabe y de su mala intelección de algunos términos. Escribe entonces Ibrāhïm: "y serán alŷamicados como se vene [¿sic? = ¿ven? ¿viene?] de una tierra a otra y de una ribera a otra y de un lugar a otro van los vocabulos disfrasados" esto es, los vocablos cambian de forma según la zona en la que uno se encuentre, mutan su morfología de una tierra a otra o bien, aclara Reminŷo, "de una ribera a otra". Esta alusión creo que a la Ribera del Ebro como frontera natural sólo puede venir, a nuestro juicio, de alguien que la conoce desde ambos lados y que puede ser consciente de las peculiaridades lingüísticas de cada zona.

Por otra parte, en esta misma parte del texto y en otra, están las claras referencias a Francia. Si son primero, en el texto que veremos más adelante, unos cardenales franceses los que parecen convencer al Papa para que firme un decreto de conversión obligatoria de los mudéjares, más adelante, volviendo a hablar de esa conversión general y forzada, escribe lbrāhỉm: "...que vino a todos en general que mandaban batear a todo muçlim, que los ajenassen a Françia sin probiçión ni dinero..."32 esto es, vino una orden de expulsión general de todos los musulmanes, pero esta expulsión no a cualquier lugar ajeno, sino concretamente a Francia. Pienso que la mención de un destino tan concreto sólo puede hacer referencia a una comunidad que tenía al reino de Francia como una tierra próxima y familiar, a la comunidad de mudéjares navarros que hubo de plantearse si su exilio habría de hacerlo por el cercano sur o por el vecino norte.

De esta manera, si tomamos como punto de partida la nacionalidad navarra del alfaquí Ibrāhỉm de Reminŷo huido a Aragón, los datos que se han venido utilizando para datar el texto del Breve Compendio pueden ser con-

31. Ibidem.

32. Breve Compendio, fol. 240r. apud Jacqueline KARP, El manuscrito..., p. 40. 
templados desde otro punto de vista. Como es sabido y se ha repetido aquí, la principal fuente de estos datos es el notable pasaje del manuscrito de Cambridge que hemos usado fragmentariamente hasta ahora y en el cual Bray de Reminŷo nos relata una conversación que tuvo tiempo atrás, probablemente en Cadreita, con un fraile carmelita amigo de su familia, amigo al que trata con extrema familiaridad:

"Acuérdome del año de nuestra conversión 33 que un amigo mío muy onrrado, con quien yo tenía grande amistad, y era frayle de los Carmelitas, que se dezía fray Esteban Martel, muy amigo de los moros deste reyno más que a las otras partes, y como supo que nos abían sentensiado para que fuésemos cristianos por fuersa, embióme el amor [ $i s i c ?=i$ a llamar?] con un criado de la casa de su padre, que yo residía en la alȳama ${ }^{c} a$ de Cadrete en aquella sazón. Yo hize luego lo que debía, y llegando a su casa, donde me aguardaba, así como me bio, me hizo gran salutasión, y tomóse a llorar, medio cubierto su senblante, y hízome sentar a su mesa, que era ora de comer, y dióme granadas y confitura de Valensia, y la postre un pedaso de carne asada, aunque él no la comía, por ser aquél domingo de su pasión. Después de aber comido, entramos en el estudio de la casa de su padre, y con lágrimas me dixo: ¿qué os parese señor Bray, desta comotansa y poca cristiandad que an usado con vosotros? Yo digo de mi parte, con dolor de mi corasón y de mi ánima, que os an echo gran sinrrazón. Yo le respondí que me espantaba de su santidad aber consedido y decretado tal cosa, y respondióme que el Papa no abía consentido en ello, sino que por el decreto Mantuano nos abían sentensiado y que firmó su santedad la sentensia por engaño de siertos cardenales franseses que conspiraron contra nosotros. $Y$ después de muchas cosas le dixe que abían mirado mal por la onrra de su Dios, y debían bastar los denuestos que le hazían cada año por las calles, y me respondió, más avisado de lo que yo pensaba, diziendo que no éramos en tiempo de grasias, sino de lloros. Y tuvo este amigo tanta compasión de nosotros, que no sesaba yamás delante los perlados y cabildos de argucir y distinar contra todos aquéllos que tal consintieron, y hizo conbocansa con otros muchos para hazer comotansa y redeargucir contra su maŷestad y sus asistentes, y lo hiziera, sino que murió de allí a dos meses, y me encomendo le hiziese obsequias si acaso moría, porque le vesité en su enfermedad, y yo lloré su muerte, porque fue muy leal amigo. Y después acá siempre fue nuestro addìn flaqueando, y serraron las mesquidas dentro de tres meses, por lo cual muchos calimes se desayonaron, hasta que fue su duelo reposado, y yo comensé esta obra ocho años después de la dicha conversión, con ayuda de un escolano de buena doctrina, avisado y de largo sarhe; era natural de Arévalo, y dezía que su madre fue cristiana veynte sinco años, y con su ayuda hize lo más desta copilasión, a loor y grasia de nuestro grande y verdadero Allāh, señalando algunas aleyas de nuestro onrrado alquren, de donde se tomó lo más deste conpendio, en espesial los actos del serbisio que se debe a su dibina bondad, con las demás virtudes que pude alegar de autores graves, calimes, nahues y tafsires antigos, y otros volumes de los usos alýamacales, que todo venía por mano diestra examinado y usado con decreto nahual,

33. Nota del copista al margen: "cuando nos baptizaron". 
reformándolo todo lo meŷor estilo que supe coleŷir, por la grande ansianidad de los vocablos que defendían contra nuestro trabayo, no porque no tuvieron aquellos meyores cabidas de siensia y prudensia que nosotros, sino que era nesesario remedar aquellos vocabulos y volverlos a nuestro tiempo. Al fin, no desanparando nuestro onrrado alquren, proseguimos esta obra hasta que Allah nos de parzida contra la temoransa de nuestros enemigos, que ya comensaban a distinar contra nosotros con pugnensias de ribtos cada ora, y nos enplazaban por casos leves, vedándonos sus mesmas libertades, y revocándonos toda derechura. Pues si acaso en este compendio se hallara alguna demensia, a más de los vocabulos mal derivados, remítanlo a lo más sierto con silensio, hasta que se vea la duda lo meŷor que puedan, de mano en mano comunicándolo con quien meŷor entienda nuestra ley y sunna, y también puede aber yerro en los vocabulos mal entendidos, y serán alŷamicados como se vene [ $i$ sic ? $=$ ¿ven? ¿viene?] de una tierra a otra y de una ribera a otra y de un lugar a otro, van los vocabulos disfrasados, en espesial en España, que hurtan de todas las lenguas, y por esta vía se suelen menguar las escribturas y van a dar contra los escritores. Y por esta causa debía dezir ${ }^{\circ}$ Omar Bey: e fiado mi siensia en ŷente pobre, y con lisensia de Allāh dixo más: el leedor que estará sobre duda hinque un clabo hasta que sea absuelto" 34 .

Tomando como punto de partida que la conversión a la que se refiere el texto es la conversión forzada de los mudéjares aragoneses, Harvey postulaba que la conversación debió de tener lugar en los años 1525 ó 1526, a los que si se añadían los "ocho años después" a los que se refiere el texto nos daba los años entre 1533 y 1535 como fecha de redacción del manuscrito ${ }^{35}$. Ahora bien, si pensamos que la conversión obligada a la que se refieren Ibrā him y fray Esteban Martel es la de los mudéjares navarros, tenemos una fecha diez años anterior a la propuesta. Como hemos visto, en 1515, tras la conquista por parte del duque de Alba, las leyes castellanas pasan a regir a Navarra y, por tanto, los moriscos son obligados a elegir entre la conversión o el destierro. Si pensamos en ésta como la fecha aproximada en la que tuvo lugar la conversación y le añadimos los ocho años de los que habla Reminŷo, tenemos 1523 como la fecha más temprana en que se comenzaría a escribir el Breve Compendio. Es decir, una fecha en la que si bien ya estaba cercano el fin del estatus mudéjar aragonés, todavía los musulmanes de aquel reino podían mantener su fe públicamente.

$Y$ es que, creo, nada de lo que conocemos del texto del manuscrito de Cambridge nos obliga a pensar que en el momento de su redacción el islam esté completamente vedado en las tierras aragonesas. Si se lee detenidamente el texto anterior, se comprueba que el alfaquí Ibrāhỉm pide ayuda a Dios porque los enemigos de la comunidad musulmana comenzaban, digamos, a polemizar o a actuar contra ellos, por cuestiones de ritos o por casos leves,

34. Breve Compendio, ff. 4r.-5v. apud L.P. HARVEY, «Un manuscrito...», pp. 69-70.

35. Vid., sin embargo, una última matización planteando un adelantamiento de la fecha, hasta antes de 1525, hecha por el propio HARVEY en «El alfaquí...», p. 218. 
vedando sus libertades y revocando sus derechos (toda derechura): es decir, que en el momento de redacción de la obra, la comunidad islámica aragonesa todavía tiene libertades y derechos, es todavía una comunidad mudéjar que, aunque va viendo paulatinamente recortados sus usos religiosos, todavía puede profesar públicamente su fe musulmana en los años inmediatamente anteriores a 1525. Lo que Ibrāhīm está viviendo en el momento que compuso su tratado islámico es esa fase final del mudejarismo aragonés en la cual la práctica islámica estaba ya erosionada y amenazada, pero continuaba siendo legal.

Para sostener esta afirmación pueden ser extrapolados otros indicios a partir del Breve Compendio: en primer lugar, el hecho mismo de que el alfaquí navarro y el mancebo castellano compongan un libro, posiblemente por encargo de la comunidad musulmana aragonesa, y consensuado y corregido por esta misma, es un dato que parece llevarnos de forma inequívoca a la época mudéjar, en la que fueron escritos la gran mayoría de los textos aljamiados que fueron posteriormente, ya en época morisca, copiados de forma sucesiva.

Asimismo, la declaración que hemos visto de Ibrāhỉm en el sentido de haber encontrado consuelo por estar en tierras de Aragón escuchando una jutba el día de la reunión de la comunidad islámica ("un día de alŷumu'a") no parece ser la de alguien que se encuentra dentro de una comunidad que ha de mantener a toda costa oculta su fe islámica.

Todos estos datos, pues, nos llevan a la conclusión de que Ibrāhỉm de Reminŷo fue un alfaquí navarro que, tras el mandamiento de expulsión de los mudéjares de Navarra en 1515, cruzó la frontera en dirección a Aragón, donde se estableció y donde años más tarde, en 1523 ó 1524, emprende la redacción de un compendio de la ley musulmana en colaboración con el Mancebo de Arévalo.

\section{IBRĀHITM DE REMINŶO Y EL MANCEBO DE ARÉVALO}

Una colaboración ésta para escribir un tratado que, sin embargo, no ha podido ser evaluada con exactitud. A excepción de aquellos fragmentos en los que aparece el nombre explícito de uno u otro autor o algún dato concretísimo que puede ser adscrito sin dudas a uno de ellos, lo cierto es que la obra aparece como un continuum en el que en ningún momento se hacen afirmaciones de autoría parcial de tal o cual parte del tratado.

Conviene, empero, fijarse de nuevo en el encabezamiento del Breve Compendio puesto que es él la más firme referencia que seguimos teniendo en este punto. Según este texto, la responsabilidad material total de la obra, es decir, quien "acopiló" el texto, recae sobre el alfaquí Ibrāhỉm de Reminŷo. Para esta labor fue ayudado por muchos "calimes" del reino de Aragón y, en 
especial, por el Mancebo de Arévalo. De qué índole fue esta ayuda es algo que hemos de suponer nosotros, pero quien ha redactado estas líneas parece poner conceptualmente al mismo nivel ambas ayudas, poniendo sobre la del Mancebo un acento intensificativo. Es decir, que si podemos suponer que los "muchos calimes" no le ayudaron a redactar su texto, cabe también esta misma suposición para el Mancebo.

De hecho, los verbos que aparecen en el Breve Compendio haciendo referencia a su manufactura concreta (i.e. "acopiló", "comensé esta obra", "hize lo más desta copilasión", "virtudes que pude alegar de autores grabes", "rreformándolo todo lo que meŷor estilo que supe coleŷir"...) están en singular y hacen referencia clara a Ibrāhīm, mientras que el Mancebo es siempre presentado al lado del verbo "ayudar". Naturalmente, es conocido que hay fragmentos del manuscrito que presentan vivencias del Mancebo en primera persona, con la apariencia de haber sido relatadas por él mismo, lo que ha llevado siempre a la crítica a la cuestión de que quién es el que está escribiendo en cada momento.

Creo que la respuesta se halla en estos mismos dos verbos que hemos empleado: relatar y escribir, dos fases distintas, pero que pueden ser complementarias a la hora de la composición de un texto. Nuestra hipótesis es que el Breve Compendio de Nuestra Santa Ley y Sunna es todo él la obra material de un solo autor: el alfaquí navarro Ibrāhim de Reminŷo, quien, impelido a escribir un tratado legislativo islámico en Aragón, acude a cuantas personas puedan ayudarle en su tarea, en especial personas que puedan proporcionarle un bagaje, oral o escrito, en el cual basarse.

$Y$ entre estas personas especialmente el Mancebo de Arévalo. Por qué, de pronto, dos personas ajenas a la comunidad mudéjar aragonesa intervienen en la composición de un tratado a ella destinado no podemos saberlo con certidumbre. Indudablemente sobre sus personas debía de recaer cierta fama de hombres cultivados en el árabe y en el islam y, a tenor del Breve Compendio y las obras del Mancebo, a ellos esa fama no debía de molestarles demasiado ni se preocupaban de si era o no justificada.

Es posible que la fama del Mancebo viniera, aparte, por supuesto, de su propia autopropaganda, de haber sido quien llevara y propagara en Aragón el Breviario Sunní de Içe Gidelli, uno de los textos que es utilizado con profusión para la confección del Breve Compendio ${ }^{36}$, aun cuando Ibrāhīm aparece afirmar que es la suya la primera traslación y compilación que sobre estos temas se hace en castellano:

36. Vid. L.P. HARVEY, «El mancebo de Arévalo y la tradición cultural de los moriscos», Actas del Coloquio Internacional sobre Literatura Aljamiada y Morisca, Madrid, 1978, pp. 20-41; G. WIEGERS, Yçe Gidelli..., pp. 160-162; id. «Isà b. Ŷẩir and the Origins of Aljamiado Literature», Al-Qantara, XI, 1, 1990, pp. 155-191. 
"lo más deste conpendio salió de las dichas aleyas y no salió todo del trabajo mío, que yo hallé sarjes en muchos alquitebes / carábigos y aljemicados reposados, que departían muchas cosas de las que aquí son contenidas en este conpendio, y aunque van los dichos descarriados por ser esta la primera traslasión, no lo atribuyen a poca curiosidad, porque no puede una lectura satisfazerse de la primera alluhada, mas ya podrá cualquier mediana siensia o entendimiento referir y dar salida, pues no tiene que rastrear siensia de ningún arte, porque todo está abocado en el entendimiento natural, sólo que los dichos no se pueden bien ermanar por ser ésta la primera copilasión y los vocablos de muchas tierras" ${ }^{\prime 37}$.

De la misma forma, quizá la patria navarra de Reminŷo, donde aún se conservaba algo la lengua árabe entre los alfaquíes-escribanos (no, ciertamente, en él), le sirviera como timbre de honor entre los menos expertos mudéjares aragoneses que les acogieron.

El hecho es que, sea por la razón que fuere, Ibrāhimm se lanza a redactar un tratado doctrinal legislativo, digamos, "aragonés", que se basa en sus principales líneas en la obra del muftí castellano Içe Gidelli o Içe de Gebir. Teniendo en cuenta las dificultades de las que nos habla Ibrāhim en torno al trasvasar vocablos aljamiados de otras partes (de España, podemos pensar), cabe imaginar que la primera "ayuda" que le prestó el Mancebo, siempre dispuesto a "explicar", fue el asesorarle en los términos islámicos castellanos que contiene el Breviario Sunní para poder trasvasarlos adecuadamente en el sistema aljamiado aragonés. Es decir, que tendríamos en Ibrāhỉm una verdadera labor de redactor y "editor" de textos, de hombre que es capaz de vertir diversas fuentes orales o escritas al sistema aljamiado de Aragón.

Pero, sin duda, este "asesoramiento" del Mancebo a Ibrähïm no acabaría ahí. Como es sabido, la característica principal que ha sido resaltada de las obras del Mancebo de Arévalo es su uso un tanto peculiar de las fuentes que aduce como de sabiduría islámica tanto para la Tafçira como para el Sumario de la relación y ejercicio espiritual: al-Gazzali, Ibn 'Arabī o el extraño y misterioso nombre de 'Umar Bey, entre otras fuentes, son los nombres míti$\cos$ que utiliza profusamente el autor castellano para encubrir su conocimiento de la devotio moderna y, en especial, de Tomás de Kempis ${ }^{38}$, corriente espiritual y espiritualista que, como demuestra la profesora María Jesús Rubiera en este mismo volumen, recorre, vertebrándola, toda la obra del Mancebo.

$Y$ estas citas de autoridad ficticias, míticas pero irreales, aparecen también en el Breve Compendio, si bien en menor cantidad que en las obras del

37. Breve Compendio, ff. 2v.-3r. apud L. P. HARVEY, «Un manuscrito...», p. 67.

38. Vid. Gregorio FONSECA, 'Sumario de la relación y ejercicio espiritual sacado y declarado por el Mancebo de Arévalo' (Edición y estudio del ms. B.N.M. Res 245), Oviedo, 1987 (Tesis doctoral inédita). 
Mancebo: posiblemente, la simple acomodación de la obra legislativa de Içe Gidelli debió de parecer poco a los dos foráneos de Aragón, quienes, quizá para impresionar a los aragoneses, decidieron insuflar la obra de ejemplares historias personales, aquí de Reminŷo, más allá del Mancebo, difíciles de comprobar en la realidad ${ }^{39}$, y eruditas citas islámicas.

Ya hemos visto que los escrúpulos de Ibrāhỉm declarando que su obra aljamiada es la primera de su estilo no son muchos, escrúpulos por los que el Mancebo tampoco parece sentir demasiado aprecio. Pensamos que a partir de la redacción de esta obra por parte de Ibrāhĩm -obra legislativa en su mayor parte, pero trufada tanto de historias propias como narradas a él por el Mancebo-, el de Arévalo debió de aprender y comprender las posibilidades del sistema que le estaba enseñando el alfaquí navarro en la redacción aljamiada de un tratado islámico: unas posibilidades que le permitirían más adelante, ya en época morisca, componer sus propias obras no en la línea legislativa propia de Reminŷo, sino en la línea plena de espiritualidad propia del autor castellano.

Con el Breve Compendio de nuestra Santa Ley y Sunna creo que estamos ante un momento singular del mudejarismo hispano y de la literatura aljamiada. Justo en el momento de máximo decaimiento del islam mudéjar, en Aragón unen sus fuerzas dos singulares personajes para crear un corpus legislativo islámico a semejanza del que existía en Castilla: un redactor de origen navarro, posiblemente más apegado a la estricta redacción de las normas, pero quizá impresionado y, sin duda, influido por las citas islámicas de un castellano de buena formación y aguzado ingenio, quien, tras esta primera experiencia como parte de las voces del Breve Compendio, llevará más adelante a la literatura aljamiada, entonces también morisca, a realizaciones de una altura insospechada.

39. Con esto no quiero decir que todas las historias y anécdotas personales que aparecen tanto en el Breve Compendio como en las obras del Mancebo de Arévalo sean una pura invención, sino que, dada la demostrada inclinación al encubrimiento que padecen estos textos, se debe obrar con cautela a la hora de aceptar como cierto (por lo menos estrictamente cierto) todo lo narrado por el Mancebo y por Ibrahìm. Un ejemplo: en el relato de Reminŷo con el carmelita Esteban Martel, se ha repetido siempre, puesto que no se ha hallado otra noticia sobre él, la propuesta de María Soledad Carrasco en el sentido de relacionarlo con la acaudalada familia aragonesa del cronista Jerónimo Martel, "decidido partidario de las libertades aragonesas" (El problema morisco en Aragón al comienzo del reinado de Felipe II, North Carolina, 1969, p. 43). Sin embargo, otra persona pudo llevar ese apellido, y, curiosamente, otro religioso cristiano: el sacerdote Nicolau Martel (o Martil, puesto que el esquema consonántico árabe admite varias lecturas), profesor criptomusulmán que enseña a fray Anselm Turmeda, convertido después al islam como ${ }^{C}$ Abdallăh al-Tarŷumān, que el Paráclito esperado será Muhammad y le impone la obligación de convertirse al islam: Míkel DE EPALZA, Fray Anselm Turmeda ('Abdallāh al-Tarŷumān) y su polémica islamo-cristiana. Edición, traducción y estudio de la Tuhfa, Roma, 1971; Madrid, 1994, pp. 208-222. No se trata de afirmar ningún tipo de influencia de un autor sobre otro (la Tuhfa parece ser que no fue conocida en la Península Ibérica pese a su gran fama en el islam), sino de insistir en la precaución que demandan unos autores como el Mancebo y Reminyo. 